\title{
Range of variation for total antioxidants status and few metabolites implicated in oxidative processes in neurodegenerative diseases
}

\author{
Ioana Varga ${ }^{1}$, Ana Maria Szabo $^{2}$, Georgeta Sofia Pintilie (Popescu) ${ }^{3}$ and Iulian Ionescu ${ }^{4}$ \\ ${ }^{1}$ Neurology and Psychiatry Hospital, Faculty of Medicine, Transilvania University, Brasov, 7-9 Prundului Street, Brasov, \\ Romania, ${ }^{2}$ Centre for Neuro-Muscular Diseases 'Dr. Horia RADU', 527175 Vâlcele, Jud, Covasna, Romania, ${ }^{3}$ Department \\ of Biochemistry and Human Nutrition, Faculty of Food Products Technology, University of Agricultural Science and \\ Veterinary Medicine Timişoara, 119 Calea Aradului, 300 645, Timisoara and ${ }^{4}$ The West Medical Centre - 1 Calea \\ Fagarasului, Brasov
}

Background and purpose: Free radical levels in the body must be tightly controlled, as their highly reactive nature makes them a potential threat to healthy body tissues. The body has an integrated antioxidant system to control free radical levels and neutralises excess by several components including enzymes, metal binding proteins and others.

When antioxidant reserves in the body become unable to control free radical levels, they can cause serious damage at the cellular level. Clinical treatment of disease generally involves treating the symptom and not the cause of the problem.

The aim of this study was to test the normal range for total antioxidants status (TAS) in 19 subjects. This range will be used in a multifactorial study concerning the oxidative stress in several neurological diseases multiple sclerosis and amyotrophic lateral sclerosis.

The other intend of this paper is to introduce an antioxidant supportive therapy (based on the nutritional factors in terms of neuroprotection) able to modulate the immune response in these diseases.

Methods: Total antioxidant status of blood plasma was assessed in 19 subjects defined as being free of major medical or surgical illness within 5 years and leading an active and independent life. We investigated also few metabolites implicated in the oxidative processes.

Results: The plasma TAS was ranged between 1.40 and $1.80 \mathrm{mmol} / \mathrm{l}$ in plasma. The variations of uric acid, albumin, copper, cholesterol and triacylglycerols concentrations in plasma seem to present a correlation with TAS.

The results of our study are presented in the table below.

\begin{tabular}{|c|c|c|c|}
\hline & Control $(n=19)$ & $\operatorname{ALS}(n=11)$ & MS $(n=16)$ \\
\hline Age (years) & Mean $\pm S D$ & $55.70 \pm 10.52$ & $45.13 \pm 7.23$ \\
\hline Albumin (g/dl) & $53.42 \pm 8.51$ & $3.99 \pm 0.54$ & $3.725 \pm 0.29$ \\
\hline Bilirubin $(\mu \mathrm{mol} / \mathrm{l})$ & $4.02 \pm 0.31$ & $11.71 \pm 1.03$ & $8.24 \pm 1.83$ \\
\hline Cholesterol (mmol/l) & $9.78 \pm 2.43$ & $4.57 \pm 0.80$ & $4.83 \pm 0.90$ \\
\hline Copper $(\mu \mathrm{g} / \mathrm{dl})$ & $4.99 \pm 0.21$ & $101.45 \pm 0.79$ & $119.50 \pm 11.02$ \\
\hline $\mathrm{CRP}(\mathrm{mg} / \mathrm{l})$ & $125.41 \pm 18.15$ & $8.20 \pm 0.63$ & $7.10 \pm 1.04$ \\
\hline HDL-cholesterol (mmol/l) & $6.89 \pm 1.35$ & $1.19 \pm 0.79$ & $0.62 \pm 0.24$ \\
\hline LDL-cholesterol (mmol/l) & $1.59 \pm 0.35$ & $1.19 \pm 0.79$ & $3.64 \pm 0.84$ \\
\hline Phospholipids (mmol/l) & $3.05 \pm 0.37$ & $4.94 \pm 0.23$ & $3.03 \pm 0.78$ \\
\hline $\mathrm{SH}(\mu \mathrm{mol} / \mathrm{l})$ & $4.94 \pm 0.23$ & $290.71 \pm 62.60$ & $199.49 \pm 8.30$ \\
\hline TAS $(\mathrm{mmol} / \mathrm{l})$ & $303 \pm 40.58$ & $1.72 \pm 0.29$ & $1.12 \pm 0.18$ \\
\hline Triglycerides (mmol/l) & $1.61 \pm 0.14$ & $1.27 \pm 0.63$ & $1.24 \pm 0.71$ \\
\hline Uric acid $(\mu \mathrm{mol} / \mathrm{l})$ & $1.68 \pm 0.17$ & $245.49 \pm 66.35$ & $293.73 \pm 29.0$ \\
\hline
\end{tabular}

Conclusions: TAS level was determined by the colorimetric method in the serum from 11 ALS patients, 16 MS patients and 19 healthy control group subjects. The study revealed that serum TAS level was significantly higher in ALS and lower in MS patients compared with that in controls $(P<0.05)$.

We also observed a diminution of $\mathrm{SH}$-free and uric acid concentration (more evident in the MS patients, $P<0.05$ ) and a slight diminution of copper, compared with the control group. 